\title{
An Examination of the Protection of Labor Rights and Interests of Residents in Standardized Training
}

\author{
Qian Chen, Lei Feng \\ School of Public Health and Management, Chongqing Medical University, Chongqing, China \\ Email: chenqian20170917@163.com
}

How to cite this paper: Chen, Q., \& Feng, L. (2021). An Examination of the Protection of Labor Rights and Interests of Residents in Standardized Training. American Journal of Industrial and Business Management, 11, 172-182.

https://doi.org/10.4236/ajibm.2021.112011

Received: January 18, 2021

Accepted: February 7, 2021

Published: February 10, 2021

Copyright $\odot 2021$ by author(s) and Scientific Research Publishing Inc. This work is licensed under the Creative Commons Attribution International License (CC BY 4.0).

http://creativecommons.org/licenses/by/4.0/

\begin{abstract}
As an important mode of medical personnel training in China, standardized residency training has effectively promoted the development of medical and health care in China. However, at present, China's standardized residency training system still suffers from unreasonable recognition of training relationships, uncertainty in the identity of residents, and singularity in the main body of labor rights and interests' protection, etc. There is an urgent need to improve the relevant rules and regulations to protect the legitimate labor rights and interests of residents during their standardized training.
\end{abstract}

\section{Keywords}

Standardized Residency Training, Apprenticeship Relationship, Modern Apprenticeship System, Labor Rights and Interests

\section{Preface}

On 30 March 2018, Gu, a postgraduate training student at the First People's Hospital of Zhenjiang City, Jiangsu Province, unfortunately died suddenly while handing over his shift. Gu, a second-year graduate student at Jiangsu University, was participating in residency training at Zhenjiang First People's Hospital and had been working continuously for about 14 hours at the time of the incident. After Gu's death, his relatives put forward an application for recognition of work-related injuries. For the family proposed in accordance with the compensation for work-related deaths, the hospital side replied to the family that it could not declare work-related deaths, because Gu did not have a labor contract with the hospital side and do not take pay, which does not meet the conditions for declaration. The hospital said that $\mathrm{Gu}$ is a student of Jiangsu University, the 
main unit to deal with this matter should be the university, and its academic records, files are under the management of the school. The hospital as Jiangsu University Teaching Hospital, undertakes teaching tasks, as an internship base. The case has aroused widespread concern in the community, and the public's doubts about the protection of residents' labour rights have resurfaced, with the controversy pointing directly at the inadequacies and loopholes in China's system relating to the standardized training of residents.

With the continuous development of medical and health care in China, the standardized residency training has also made considerable achievements, and as of December 2018, the total number of residents in China is 400,000, and 130,000 residents with postgraduate status in medicine (National Health and Wellness Commission, 2018), In order to implement the requirements of the "Health China 2030" planning outline, the number of residents participating in standardized residency training will continue to rise each year. In order to implement the requirements of the "Health China 2030" plan, the number of residents participating in standardized residency training will continue to rise each year, and in the face of the huge number of residents, academic research on how to better improve the standardized residency training system is in full swing. The research focuses on how to improve the motivation of residents in standardised training, how to optimise the management model and training mode of standardised residency training, and how to strictly review the qualifications of training bases. However, a literature search reveals that there is a gap in the protection of residents' labour rights and interests. Under the existing medical talent training system in China, if the government, medical schools and medical institutions want to make good use of the standardised residency training system, they must solve the problem of safeguarding the labour rights and interests of residents, and by clarifying the mode of safeguarding labour rights and interests during standardised training and the responsible body; the labour rights and interests of residents will be safeguarded in practice, so as to ultimately realise the training of medical talents. Under the standardised training model, the legal relationship between residents and training bases, residents and their respective units, and how to protect the labour rights and interests of residents are issues that need to be studied and resolved. This paper analyses and discusses these issues from the perspective of labour law, with a view to providing useful reference for the development of standardised residency training.

\section{The Essence and Origin of Standardised Residency Training}

\subsection{The Concept of Standardised Residency Training}

Standardised residency training refers to the systematic and standardised training of medical graduates, after completing their basic medical education, in a training base accredited by the health administration (including the Chinese medicine administration) at provincial level or above, with a focus on improving 
clinical competence. Residents are divided into "unit members" and "social members" according to the source of their training. The "unit members" are those residents who have signed employment contracts with their hospitals (training units). Social workers are residents who enter the base hospital for training as trainees. At the beginning of the design of the training system, there was no good interface between the postgraduate training system in the education sector and the residency training system in the training sector in China. At one time, there was a strange phenomenon that after three years of postgraduate clinical training, one had to join the undergraduate training again, which caused strong dissatisfaction among postgraduate clinical students. The solution to the problem later was to allow clinical postgraduates to attend the standardized residency training while completing their postgraduate education. At present, there are two categories of residents in China: those who work in units, those who work in society, and those who have postgraduate training status. As the relationship between the "social people" and the training base is clear, this article only discusses the "unit people" and the "training subjects with postgraduate status".

\subsection{Origins of the Residency Training System}

\subsubsection{Foreign Development}

Residency training systems have been in place since the end of the 19th century at the University of Berlin in Germany (Ma et al., 2015), and have since developed rapidly in the United States, Canada and Japan. The residency training system in the United States has been relatively well developed to date, with the Johns Hopkins Hospital opening the first residency training site in the United States in 1889. For more than 70 years, from 1889 to 1965, there was no unified management and leadership structure for residency training in the USA, nor did the government fund residency training. In 1981, the Accreditation Council for Postgraduate Medical Education (ACME) was established and its role in the management of residency training was clarified. In 1981, the Accreditation Council for Postgraduate Medical Education was formally established and its responsibilities and unified management authority for the accreditation of postgraduate medical education in the United States were clarified, and the United States has since moved towards a unified management of residency regulations (Taradejna, 2007).

\subsubsection{The Origins of Domestic Development}

In the late 20th century, China began to implement a standardised residency training system, and has made considerable progress since then. 1993-1999, the former Ministry of Health issued a series of supporting policy documents for standardised residency training, and in 2006, pilot work in three provinces and cities, namely Sichuan, Guangzhou and Beijing, provided the basis for the full implementation of standardised residency training in China. In 2009, the State Council first proposed the establishment of a standardised residency training 
system, and in 2010, Shanghai took the lead in launching a unified standardised residency training programme for post-graduate medical students. The standardised residency training will be rolled out nationwide one after another. At the same time, China will start to fully implement the standardised residency training programme from 2015.

\section{Problems Raised}

At present, the standardized residency training work has become an important way for medical graduates and doctors in primary medical institutions in China to improve their professional skills, and this medical personnel training system has been gradually converging with developed countries in the world (Yang, Huang, Niu, \& Wang, 2010). However, because of the late start and rapid development of the standardized residency training system in China, there are still many problems that need to be studied and solved, especially the problems that exist at the institutional level. The National Health and Family Planning Commission and other seven departments on the establishment of a standardized training system for resident physicians, hereinafter referred to as the "guiding opinions" pointed out that "the original personnel (labor) and salary relations of the training subjects assigned by the unit shall remain unchanged during the training period, and the commissioning unit, the training base and the training subjects shall sign a commissioning training agreement, and the salary paid by the commissioning unit shall be lower than that of the training base. The training base is responsible for paying the part of the salary of the resident with the same conditions. Training subjects with postgraduate status implement the relevant provisions of national postgraduate education, and the training base may grant them an appropriate living allowance according to the training assessment."

The Guidelines indicate a formal training relationship between the "unitary" and the training base, at least in a literal sense, by the signing of a commissioned training agreement. "Training subjects with postgraduate status" are directly excluded from the regulations governing residency, stating that they are managed in accordance with the national regulations on postgraduate education, without being explicitly given the status of resident. The ambiguity of the Guidelines regarding labour relations and the avoidance of the issue of status have led to many problems in the operation of the standardised training system.

\subsection{Standardized Residency Training Is Different from Training in the General Sense}

The training relationship is used to describe the social relationship formed between the trainer and the trainee; in other words, the training relationship arises as a result of the act of training. The essence of training can be found in the fact that training can be understood from a certain point of view as an alter ego of learning, whereby trainees are trained to improve certain aspects of their abili- 
ties. The only parties that benefit from the training are the trainee and the party that pays for the training, but there are also cases where both parties are the same, although the State is the one that benefits most from the training, as the progress of the individual will, to a certain extent, lead to the progress of the State.

In the standardised residency training system, the main interests involved include the resident, the training unit, the training base and the state, each with their own different interests. From the point of view of the state, it is to ensure the basic quality of medical personnel in order to meet the requirements of the medical and health care industry due to the development of social diseases and the health needs of the public; from the point of view of the training bases, the standardised residency training can provide cheap labour for them during the training period, reduce the cost of hospital operation and at the same time alleviate the conflicts caused by the shortage of medical personnel; from the point of view of the training units, the staff From the point of view of the resident training unit, the staff have improved their clinical skills and business, which enhances the competitiveness of the commissioning unit in the medical market; from the point of view of the resident, their personal professional ability is enhanced and their career development is more promising. In summary, it can be seen that there are at least four subjects of interest in the standardised residency training system. In contrast, there are at most 3 parties of interest in the training relationship.

In summary, it seems that residency training is the same as training in the general sense that trainees are trained to improve their abilities or acquire certain skills. However, there is a difference between the two in terms of the subjects of interest, as there are at most three subjects of interest in the training relationship arising from the act of training, whereas there are at least four subjects of interest in the standardised residency training system. It is not reasonable to ignore the difference between the two interests and confuse them, and there is no theoretical basis for this.

\subsection{Uncertain Status}

The legal status of residents refers to the status of residents as subjects of social relations in the standardized residency training system, which is the unity of rights and obligations formed by residents in their business work at the training base for the purpose of improving their clinical operation. The standardised residency training system places the "postgraduate training student" in the awkward position of being both a "student" and a "resident", and there is no uniform definition of his or her identity. There is no uniform definition of their status.

The Guidelines are silent on the issue of the status of residents who are "training subjects with postgraduate status". However, the Guidelines for Postgraduate Training in Clinical Medicine issued by the Ministry of Education of 
the People's Republic of China affirms the identity of residents who are "training subjects with postgraduate status", whether their identity is "students" or "residents". Is their status a "student" or a "resident"? The ambiguity of this status has led to a lack of legal protection of labour rights. In today's society, the rights and interests of individuals are null and void if they are not protected by relevant laws and regulations. In the implementation of the standardised training system, if the identity of the "training subject with postgraduate status" is not clearly defined, the legal remedy and protection function will be hindered or even helpless when their labour rights are damaged, which will also become an obstacle to the establishment of a good relationship between the training base, the school and the student, and will seriously In practice, the "post-graduate training students" are not only motivated to participate in the standardised training, but also hinder the development of the standardised training system for resident doctors in China.

In practice, the status of residents with postgraduate status is overlooked. Schools and training bases overemphasise their status as students and ignore their role as workers, treating the process of standardised training as an extension of the school's teaching behaviour. The labour act is not recognised and there is no decisive condition for talking about the existence of a labour relationship. In the face of the current one-size-fits-all model of determining labour relations, which is "if there is a labour relationship, it is protected, but if there is not, it is not protected" (Li, 2016), the labour rights of medical postgraduates in standardised training will not be protected by the law for a long time. This means that the labor rights and interests of the huge number of medical postgraduates during the standardized training will not be protected.

\subsection{Single Subject of Labour Rights and Interests Protection}

The single subject of labour rights protection is not in line with the value of "who benefits, who pays", which is also a reflection of the basic spirit of the law. The training base is only required to pay back the wages of the "unit" under certain conditions, while the other labour rights and interests enjoyed by the workers are solely the responsibility of the training unit to guarantee their implementation. The training base has become the object of public "envy", a subject with rights but not obligations, the point being that it is a right granted by public authority and exists legally. As two parties whose interests are regulated by the same rules and regulations, the existence of an object of "envy" must be accompanied by the existence of a "poor" individual who makes people feel compassionate. The public is always in the habit of making itself the protagonist of an event, of trying to empathise with the different owners and of expressing its attitude. The commissioning unit is the "poor" protagonist who has aroused the public's compassion, and there is no denying that the commissioning unit does appear to be quite "aggrieved" under such regulations. After all, because the "unit of people" in the standardised training during the implementation of the conduct of the beneficiary subject is not only themselves, the training base is also 
a major beneficiary of the subject, the same as the benefits of the two sides in the distribution of responsibility for such a large gap, will inevitably cause people to resist. The lopsided approach of the rules and regulations is clearly contrary to the principle of fairness in law and to the public's true perception of fairness.

\section{The Path to Restructuring: Introducing Apprenticeships and Giving Residents a Proper Name}

\subsection{The Gap in Labour Law}

According to the nature of their work, residents' labour rights and interests should be protected as if they were regular employees of the training base. Residents follow the various labour rules of the training base, receive the management of the training base and complete their work within the scope of their duties, and the training base should assume the obligation to protect residents' labour rights and interests. In the course of their work, residents come into contact with all kinds of medical equipment, face a variety of patients and, due to the special nature of their work, work overtime and late nights are commonplace, and even when they work in strict accordance with professional regulations, safety accidents of varying degrees may occur.

However, the current labour law is a legal code that regulates labour relations, which is the relationship of rights and obligations between the employer and the worker as a result of their labour practices. Residency training, as a new form of employment, brings fundamental and transformative challenges to the recognition of labour relations in labour law. Although residents differ in some aspects from workers in the sense of traditional labour law, their labour rights and interests should also be protected by law, but the social relationship between residents and training bases should not be simply identified as labour relations, to prevent the situation where labour relations are identified too broadly. The consensus reached implies two fundamentally divergent ideas. One is that the enhancement of physicians' professional competence comes first, which caters to the objective human need for superb medical skills, and that this new model of medical personnel training, which is still immature, cannot be restricted or stifled in the name of labour protection, and therefore the identification of a labour relationship between residents and training bases may become "the last straw that crushed the standardised residency training model"; secondly, labour protection. In the socialist market economy developed to the present day extent, workers' already have a strong sense of subjectivity, not to mention, residents are a group of people who have received higher education and have an even stronger sense of subjectivity, constantly asserting their interests in their work. As a labour law with an air of substantive justice should be innovative and breakthrough in theory, identifying residents as workers and including them in the protection category. Alternatively, the relationship between the resident and the training base should be clearly identified in law, so as to better protect the resident's labour rights and interests. 


\subsection{Introduce an Apprenticeship Relationship to Give Residents a Proper Name}

At present, the road to safeguard the labour rights of residents in China is slightly bumpy. If the rights of residents are defended under the Labour Law, judges are often bound by the determination of the labour relationship between residents and training bases and make judgments against residents or do not accept them at all. When protected by the Tort Liability Law, residents will find it difficult to prove the burden of proof, while tort liability is difficult to clarify. The author believes that the relationship between residents and training bases should be recognized as an "apprenticeship" in order to repair the legal loopholes and develop a scientific and feasible legal protection mechanism and management system for residents, which is important for safeguarding the legal interests of residents, protecting the legitimate interests of participants in the system and stimulating the enthusiasm of all interested parties to participate. It is of great importance to protect the legal interests of residents, protect the legitimate interests of those involved in the system and stimulate the participation of all interested parties.

\subsubsection{The Modern Apprenticeship System}

The germ of the apprenticeship training model emerged in the early days of the founding of the country, when China decided to follow the path of industrialisation in a socialist planned economy. The apprenticeship training model quickly emerged as an advantage for its ability to quickly train mature workers, and was favoured and valued. After the reform and opening up, the apprenticeship model continued to exist in the form of vocational and technical education.

During the two stages of development of the apprenticeship system, the training model underwent certain changes in form. Initially, the entire training process was carried out in factories, where apprentices learned skills and appreciated theoretical knowledge in practical operations; later, it was divided into two stages, with theoretical knowledge being completed in vocational colleges and then practical operations in enterprises to improve familiarity with operations. Although the training approach has changed, it is clear that both training models aim to emphasise the "learning" aspect of the apprenticeship. A new high point in the development of apprenticeships came in 2014, when the State Council issued a document identifying a pilot modern apprenticeship system. The main content of the modern apprenticeship pilot work is "enrollment is recruitment, into the school is into the factory, school-enterprise joint training" or "recruitment is enrollment, into the enterprise is into the school, enterprise school double teacher joint training" (Chen \& Han, 2015), that is vocational college students when entering the school has been determined, In other words, when students enter the school, they have already decided which enterprise they will work for, and after successfully completing their studies, they can become full employees of the enterprise. At the same time, the dual identity of the apprentice enterprise employee as well as the school student is also affirmed in the 
Ministry of Education's “Opinions of the Ministry of Education on Launching the Pilot Work of Modern Apprenticeship" released in 2014. Before vocational college students enter the enterprise as apprentices, a contract needs to be signed between the student and the school, and between the school and the enterprise to determine the rights and obligations of each party and to protect the interests of each party (Ministry of Education of the PRC, 2014).

\subsubsection{Incorporating Standardised Residency Training into the Modern Apprenticeship System}

A distinction is made between the pathway for medical personnel to improve their professional skills after graduation, which is named the standardised residency training system, and the process of familiarising vocational college students with their professional skills, which is called the modern apprenticeship system. In fact, the two are essentially the same, and in my opinion, they are basically the same model of talent training, and it is not appropriate to make detailed theoretical distinctions, but to do so would create some "strange" problems.

Firstly, they both aim to improve practical skills. Residency training is the process by which doctors or postgraduate medical students in primary care institutions improve their professional skills by studying medical knowledge and optimising the management of medical conditions under the guidance of a supervising teacher in a training base as a resident. Modern apprenticeship, on the other hand, is a system whereby students from vocational institutions, after completing their vocational theoretical studies at school, enter a company as apprentices to combine theoretical knowledge with practice and to continuously practice and familiarise themselves with practical operations. Both are guided by others, on the one hand, to expand their theoretical knowledge; on the other hand, to continuously practice and improve their operation.

Then again, both pass through certain bridges in order to enter the unit of study. With the implementation of the standardised residency training system, it is only then that in-service doctors from primary hospitals have the opportunity to study at higher-level hospitals and improve themselves; and postgraduate medical students can therefore learn clinical handling skills at the training base as students, synchronising theoretical learning with practical practice, integrating the two and greatly enhancing the efficiency of learning. It also avoids the awkward situation of having to attend standardised residency training even after completing postgraduate studies, in the context of an effective interface between the standardised residency training system and the postgraduate medical training programme. Under the modern apprenticeship system, students in vocational colleges are identified with the companies they intend to work for after graduation when they enter the school, and once they have completed their theoretical knowledge within the school, they enter the company to learn and familiarise themselves with practical operations. Without the modern apprenticeship system, it would be very difficult for students in vocational colleges to have the op- 
portunity to go to an enterprise for operational learning.

Finally, the labour practices offered by both are somewhat flawed. There is still a large gap between the level of professional competence of primary care physicians and postgraduate medical students and the formal physicians at the training base (Sun, Wu, \& Liu, 2012) and because of this lack of competence, the labour acts of both create unequal value for the training base. The value created by the resident's work is lower than that of the regular physician's. The resident needs to be authorised by a superior physician in the department to carry out medical acts independently, and the medical recommendations made need to be reviewed and approved by the superior physician before they can be implemented. In the modern apprenticeship system, the apprentice, after completing the theoretical knowledge in the vocational college, enters the enterprise as a novice with unfamiliar business skills, or even as a stranger to the workplace, and needs to operate machinery and complete work tasks under the guidance of senior employees.

Based on the above comparison between the standardised residency training system and the modern apprenticeship system, it is clear that the two are identical in nature and training methods, and that distinguishing between the two and trying out different systems would cause a lot of unnecessary trouble.

\section{Recommendations for the Protection of Residents' Labour Rights}

\subsection{Legally Conferred Status}

Because of their status, there is a big gap between their treatment in the training base and that of "unit staff", which makes them lack the motivation to work and a sense of belonging ( $\mathrm{Li}$ et al., 2016). The legal system for residents should give them the status of resident physicians, so that they can enjoy the same treatment as "unit staff" at the training base and receive equal pay for equal work ( $\mathrm{Hu}$, Chen, Wang, \& Xie, 2013). At the same time, the dual identity of the resident can be implemented, so that he or she can enjoy the legitimate rights and interests of workers.

\subsection{Defining the Status of Resident Apprentices}

The residency standardized training system is, in essence, a branch of the apprenticeship training model, which belongs to the talent training model in the medical field. Separating residents from their apprenticeship status has caused a lot of trouble, affirming the status of resident apprentices and bringing the residency standardized training system into the scope of the modern apprenticeship training system to address the many loopholes in the current residency standardized training system.

\section{Conclusion}

At present, most of the studies on standardised residency training in China focus 
on how to manage the residents in standardised training, how to design the standardised training curriculum and how to conduct assessments, but there are few studies on how to protect the labour rights of residents during standardised training. The author hopes that this study will provide a reference for future research on the protection of residents' labour rights during standardised training.

\section{Conflicts of Interest}

The authors declare no conflicts of interest regarding the publication of this paper.

\section{References}

Chen, S., \& Han, B. L. (2015). A Comparison of "Modern Apprenticeship" and "New Apprenticeship". Vocational Education Forum, No. 28, 67-71.

Hu, W. L., Chen, D. L., Chen, Y. T., Wang, L., \& Xie, P. (2013). Research on the Difficulties and Countermeasures of "Dual-Track Integration" of Postgraduate Education and Standardized Residency Training in Clinical Medicine. Degree and Postgraduate Education, No. 2, 41-45.

Li, Q. Y., Xiao, L. H., Liu, H. L., Liu, L. J., \& Li, R. (2016). Analysis and Reflection on the Current Problems of Standardized Residency Training. China Health Career Management, 33, 374-376.

Li, Z. K. (2016). On the Connotation of the Concept of Apprenticeship in China and Legislative Investigation. Vocational Education Forum, No. 22, 39-46.

Ma, Z., Zhao, Y., Chai, C. Y., Hu, Y., \& Hu, G. D. (2015). The Characteristics of Residency Training at Home and Abroad and the Reflection and Practice of Standardized Training. China Higher Medical Education, No. 3, 12-13.

Ministry of Education of the PRC (2014). Opinions of the Ministry of Education on the Pilot Work of Modern Apprenticeship. http://www.moe.gov.cn/srcsite/A07/s7055/201408/t20140827_174583.html

National Health and Wellness Commission (2018). Response to Recommendation No.1626 of the First Session of the 13th National People's Congress. http://www.nhc.gov.cn/wjw/jiany/201812/e28aa62d1ea2480fbe589b008a16519d.shtml

Sun, Z. R., Wu, H. Y., \& Liu, S. B. (2012). Discussion on the Construction of Talent Team in Primary Medical Institutions. China Hospital Management, 32, 67-68.

Taradejna, C. (2007). History of Medical Education.

Yang, G. S., Huang, J. F., Niu, Y., \& Wang, H. (2010). Exploration of Specialized Hospitals to Adapt to the Training System of Specialized Physicians. China Hospital Management, 30, 32-33. 